Revista aSEPHallus de Orientação Lacaniana

Núcleo Sephora de Pesquisa sobre o Moderno e o Contemporâneo

ISSN 1809 - $709 \mathrm{X}$

\title{
O feminismo e seus destinos
}

Márcia Infante Vieira

Psicanalista

Psicóloga graduada pela Pontifícia Universidade Católica do Rio de Janeiro/PUC-RJ (Rio de Janeiro, Brasil) Mestre em Teoria Psicanalítica pelo Programa de Pós-graduação da Universidade Federal do Rio de Janeiro/UFRJ (Rio de Janeiro, Brasil) Membro do ISEPOL (Rio de Janeiro, Brasil)

E-mail: marciainfante@oi.com.br

Resumo: O objetivo desse trabalho é refletir sobre o discurso feminista radical, que cada vez mais encontra lugar de destaque na mídia, mas parece não refletir a posição da maioria das mulheres. Ele promove a representação do feminino e do masculino vinculados aos papéis da vítima e do dominador respectivamente. A queda do império masculino gerou perda de referências, angústia e desejo de vingança por parte dos homens. As mulheres, desencantadas e frustradas, contra-atacaram. Como efeito: o separatismo sexual.

Palavras-chave: psicanálise; feminismo radical; vítima/dominador; separatismo sexual.

\section{Féminisme et leurs destinations}

Objectif de ce travail est de réfléchir à propos du discurs féministe radical, qui de plus en plus gagne une place de premier plan dans les médias, mais qui ne semble pas refléter la position de la majorité des femmes. Il favorise la representation du féminin et du masculin liée aux rôles de la victime et du maître respectivement. La chute de l'Empire des hommes a généré une perte de références, une anxiété et un désir de vengeance de la part des hommes. Les femmes, désenchantés et frustrées, contre-attaquent. La conséquence: le séparatisme sexuel.

Mots-clés: psychanalyse; féminisme radical; victime/maître; séparatisme sexuel.

\section{The feminism and its destinations}

The aim of this work is to reflect on the radical feminist discourse that finds itself, more and more, having an outstanding place in the media, but that doesn't seem to reflect the opinion of most women. It promotes the representation of female and male figures portrayed as victim and dominator, respectively. The fall of the male emperor generated a loss of references, anxiety, and a wish for revenge from men. The women disillusioned and frustrated, have reacted by counter-attacking. As matter of fact: the sexual separation.

Key-words: psychoanalysis; radical feminist; victim/dominator; sexual separation. 


\section{O feminismo e seus destinos ${ }^{1}$ \\ Márcia Infante Vieira}

Esse trabalho identifica no movimento feminista, ocorrido em 1968, bem como em seus destinos, uma das alavancas responsáveis pelas transformações das subjetividades e dos papéis desempenhados nas parcerias amorosas entre homens e mulheres. A premissa é de que a revolução sexual operou um corte entre o moderno e o contemporâneo, uma vez que preconizou a ideologia de liberdade e igualdade de direitos para ambos os sexos. $O$ saldo aponta que a mulher ganhou muito. Adquiriu direitos, espaço público, poder aquisitivo e liberdade sexual. No entanto, algo da ordem de um mal-entendido entre homens e mulheres persistiu. $E$ é esse o passo que esse trabalho pretende. A questão é: teria o feminismo, apesar de seus inegáveis e vitoriosos avanços, se equivocado em alguns de seus rumos?

A filósofa francesa, Elisabeth Badinter (2005), em seu livro intitulado Rumo equivocado: 0 feminismo e seus destinos, fornece um eixo orientador para essa reflexão. Através de pesquisas endereçadas ao público feminino e masculino, nos continentes americano e europeu, identifica dois movimentos feministas: o liberal e o radical. Nesse trabalho percorreremos a dinâmica desses dois movimentos e suas consequências.

O projeto feminista disseminou a ideia de que as mulheres deveriam esperar que os homens fossem companheiros, entendendo, porém, que nesse companheirismo estaria incluída a satisfação de todas as suas expectativas. Neste ponto podemos situar um equívoco, na medida em que devido as diferenças de socialização entre os dois sexos, os homens não responderam a todas essas expectativas, gerando assim, como resposta, raiva e ressentimento das mulheres. Dessa feita surge um paradoxo. De um lado companheiros, ou seja, amigos e amantes, e de outro, inimigos de classe, os opressores. Diante dessa insatisfação as mulheres tornaram-se barulhentas, acrescentando ao lugar de vítima, o lugar da briguenta, que no cotidiano são nomeadas de chatas. A luta feminina visava o alcance de direitos pelas mulheres sem que esse acesso dependesse da autorização masculina. O problema, então, é pensar por que essa luta desembocou em um mundo imaginário que prescinde dos homens.

Badinter acredita que a fonte dessa radicalização é o desencanto vivido pelas mulheres revolucionárias diante da parte inalcançável do projeto feminista, uma vez que a dupla jornada de trabalho continuou sendo creditada na conta da mulher. Aliada a essa frustração acumularam-se sucessivas experiências de fracasso em relação a construção de um relacionamento onde ternura e sexo pudessem estar conjugados. Como efeito, o separatismo sexual ganhou força e questionou se a liberação sexual estaria lançando, mais ainda, a mulher num lugar de objeto da dominação masculina. Surgiu, então, na cena social a figura da vítima dessa dominação. Essa representação ganhou tamanha força que roubou o brilho das heroínas, aquelas que realizaram proezas, alcançando através do trabalho profissional o território masculino e, consequentemente, balançando a ideologia dominante. $O$ efeito dessa vitimização impede um pensar profundo sobre uma teoria da 
relação entre os sexos. A maior acusação é a de que os homens tratam as mulheres como objetos sexuais, mantendo assim, um padrão de comportamento onde poder e dominação se apresentam frequentemente. Essa abordagem refere-se à um grupo de feministas radicais que encontram resistências por parte das feministas liberais, que protestam acreditando que toda a liberdade sexual se vê ameaçada diante dessa declaração de guerra ao gênero masculino.

Em suma, o primeiro movimento feminista libertário, datado de 1968, tinha como alvo detonar o poder do patriarcado, e tanto conseguiram balançar sua base, como fazer vacilar as representações dos papéis do masculino e do feminino. O movimento que se seguiu, o feminismo radical, fez um giro nos ganhos libertários, uma vez que denunciou uma banalização da sexualidade que teria vindo a reboque da liberação das mulheres. Esse segundo grupo radical acreditou que essa libertação serviu mais aos homens do que às mulheres, que cada vez mais se colocaram como presas das caçadas masculinas, ou seja, cada vez mais objetos sexuais descartáveis. Nessa perspectiva o machismo teria passado a ser reforçado pelas próprias mulheres. Como efeito, uma diferenciação da natureza essencial de cada gênero se impôs, trazendo novamente representações tradicionais. Ao homem, o incontrolável das pulsões; à mulher, a santificação. As radicais passaram a ser vistas como mulheres virilizadas, por terem feito um corte profundo com os semblantes que sustentavam o encontro amoroso. As outras, as liberais, por buscarem tal encontro com um homem visto como um predador pelas radicais, eram acusadas de estarem plantando um novo tipo de omissão. As feministas radicais acreditaram que as liberais estavam sem voz diante de uma manipulação machista, que visava manter o domínio sobre as mulheres que os questionavam.

No livro, supracitado, a autora trabalha com o resultado de inúmeras pesquisas realizadas após a revolução sexual, no continente europeu e na América do Norte, e faz um balanço do movimento feminista e de suas implicações. O eixo é a crítica a um feminismo radical, que do seu ponto de vista, cristalizou as representações do homem e da mulher no casal dominador/vítima. Acredita que os papéis vacilaram desmapeando os estereótipos e as funções que cabiam a cada sexo na parceria. Admite que os registros de outrora, apesar de serem opressores, tranquilizavam. Identifica a queda do império masculino concomitante ao fim do patriarcado. Avalia que um cheiro de vingança pairou no ar, parecendo que as mulheres teriam que pagar a conta desse declínio. Segundo a autora, precisamos ter cuidado para não cairmos numa esparrela de guerra entre os sexos.

A questão levantada por Badinter é se as mulheres emancipadas não teriam sido duplamente tapeadas, no que se refere à divisão do trabalho doméstico e aos ganhos reais em relação à sexualidade. Seu argumento é o de que como não viam a possibilidade de retroceder em relação aos ganhos alcançados e, também, por outro lado, por não quererem sacrificar suas vidas pessoais e profissionais, seguiram em frente, apesar do desencanto. Os homens não corresponderam ao jogo da igualdade, pelo menos não tão prontamente, como desejavam. E nessa brincadeira passaram-se mais de vinte anos sem sinais de mudanças. $O$ saldo dessa equação foi a amargura e o ressentimento 
por parte das mulheres, que por sua vez dispararam uma série de acusações em direção ao sexo oposto. A obsessão em acusar os homens de dominação parece ter como efeito obscurecer a continuidade dos verdadeiros ideais de luta, uma vez que impede um pensar profundo sobre uma teoria da relação entre os sexos.

As feministas norte americanas, pioneiras do movimento de queima dos sutiãs, endossaram o coro das feministas radicais e passaram a identificar como prática de abuso sexual, quase todas as formas de cortejo e sedução vinda por parte dos homens. Chegaram a comparar a violência sofrida por abusos masculinos aos abusos cometidos em campos de concentração da época do holocausto. Como consequência: vitimização para o lado feminino e culpa, para o masculino. Badinter compara a figura dessa mulher vitimizada à criança inocente da era pré-freudiana. Ambas ingênuas, vítimas do adulto homem violento e perverso.

É bom esclarecer que, em nenhum momento, a autora discorda que os abusos reais devem ser denunciados e seus autores perversos castigados. Ela questiona a causa que é atribuída a essa dominação. A seu ver, o que está no alvo do ataque é a própria virilidade, uma vez que a violência da dominação e o abuso de poder generalizou-se para todos os homens. Essa ideia propaga a distorção de que a violência é uma questão de gênero, logo sexuada. Deste modo, a violência masculina foi sobreposta ao sexo masculino.

A palavra de ordem passou a ser "igualdade na diferença". A contracepção tornou-se a alavanca para as mulheres se apropriarem de seus corpos, tornando-se autônomas em relação a qualquer subjugação masculina. Nesse ponto identifico uma contradição: uma vez que as mulheres alcançaram essa autonomia, qual o propósito de continuarem a se apresentar como vítimas da dominação masculina? Essa conta não fecha. Minha hipótese é a de que, mais do que a supremacia masculina, a mulher não consegue se desvencilhar desse lugar, dessa representação mental da desigualdade.

A proclamada igualdade na diferença representa uma utopia, um desejo de libertação desse aprisionamento nessa categoria arcaica, comum a ambos os sexos. De 1980 em diante, a humanidade passou a ser envolvida pelo direito à diferença. Na verdade, esse clamor não passou de um sopro que foi sucumbido por uma ideologia de indeterminação dos sexos, trazendo a ameaça do sexo único, pautado no gênero masculino. A sociedade virilizou-se. A cada avanço das mulheres, os homens foram encontrando novos mecanismos de dominação, já que nunca quiseram perder "os privilégios materiais e sexuais proporcionados pela dominação sobre as mulheres" (Badinter, 2005, p. 50). Apesar desses mecanismos, a autora questiona a universalidade da dominação e violência masculina, pois, se isso procede, a humanidade encontra-se sem salvação, na medida em que esse modelo de masculinidade tradicional fica cristalizado como essencial. Não se pode negar o quanto ao longo dos últimos 50 anos, a situação e o comportamento das mulheres, do ocidente, modificouse. E o dos homens, não? Eles seriam a parte imutável da humanidade? O sexismo conduz ao equívoco, ao universalizar a prática do abuso a todos os homens, ao invés de singularmente, caso a 
caso, lutar pela condenação dos que, diferentemente dos outros, cometem abusos. Não seria esse um pensamento mais democrático? Caso contrário, ficamos fadados a lidar com a dominação masculina como um "conceito-obstáculo", devido a barreira que ele passa a exercer no sentido de uma maior reflexão sobre a complexidade, historicidade e evolução da relação entre os sexos, pois encerra homens e mulheres em dois campos opostos.

O efeito desse dualismo oposicionista foi o de ter instaurado o litígio como a base de uma moral entre os sexos. De um lado está o mal, lugar esse ocupado pelo homem dominador e, do lado do bem, estaria sua vítima oprimida, a mulher. Ficou creditado ao bem, a fidedignidade e verdade de seus depoimentos. Logo, a vítima sempre falaria a verdade, o que inclui que essa vítima é desprovida de inconsciente, sem imaginário e sem fantasias. Essa ideologia separatista não consegue reconhecer a existência de dois sexos portadores de potência e fecundidade. A encarnação dessa diferença simbólica é o que permite expressar duas maneiras diferentes de ver o mundo.

A autora lança luz sobre o que estava na sombra: as omissões. Ainda baseada nas pesquisas, ela denuncia e balança a crença de que a violência é propriedade do sexo masculino. $O$ número de homens atacados e que apanham das mulheres é muito grande. A dificuldade em se catalogar essa estatística tem dupla causa. Primeiro, não existem denúncias feitas por parte dos homens, da mesma forma que existem feitas pelas mulheres. Essa desproporção evidencia um acordo de silêncio em relação a esse assunto. Depois, os próprios homens sentem-se envergonhados de exporem que sofrem abusos por parte de uma mulher. Esse mutismo tem como causa a virilidade espoliada. Outra omissão sublinhada por Badinter é relativa ao número de mulheres que participaram dos exércitos nazistas e que se comportavam de forma violenta e abusiva com seus perseguidos. De posse desses dados a autora desvincula a violência como exclusividade do sexo masculino e conclui ser a violência um comportamento humano. Esse tabu se sustenta, uma vez que sua revelação desconstrói a própria imagem que a mulher tem de si.

De qualquer forma, encarnar como norma o que é da ordem do patológico é um outro rumo equivocado. A violência, o abuso e a humilhação fazem parte de práticas entre cônjuges que se encontram adoecidos. Muitas vezes potencializados pelo vício de drogas e álcool. Universalizar esse padrão a todos os homens mascara a diferença de registro entre o normal e o patológico, e entre o universal e o singular.

A humanidade avançou, sem dúvida. Homens e mulheres ainda se envolvem, apesar de tudo. Hoje o trabalho tem para a mulher o mesmo valor que possui para o homem. Este valor é o que Ihes confere a independência necessária para permanecerem ou sair de um vínculo de compromisso. No entanto, existem formas mais sutis de dependência, tais como: a dependência sexual, afetiva ou psicológica. Nesses casos tanto um sexo como o outro podem ocupar o lugar do dominador ou o do dominado.

Badinter acredita que deslocar a mulher do lugar de vítima não implica em abolir as denúncias de abusos e violências contra elas por parte dos homens machistas radicais. Sua 
preocupação concentra-se em não permitir a cristalização das representações da mulher vítima, pois frágil, e nem do homem dominador, poderoso. Ela crê ser um retrocesso nos avanços conquistados até então. Na verdade, o que se oculta por detrás dessa cristalização é a contradição em que as mulheres se encontram envolvidas na atualidade. Uma dupla obsessão toma conta da subjetividade feminina. De um lado, um imperativo de gozo que traz a exigência de um prazer pleno. Do outro, uma exigência de dignidade feminina que porta a ideia de sacrilégio sexual.

O mundo das fantasias ganhou o campo da realidade e toda uma política de propaganda estimulou os sujeitos a praticarem seus mais secretos sonhos. Um imperativo do gozo passou a comandar o espetáculo. $O$ desejo é temperado e aquecido constantemente. As mulheres não ficam de fora do espetáculo e exigem prazer. Seus corpos passam a ser cada vez mais produzidos e investidos na intenção de se tornarem o produto mais bem-acabado do mercado. A aparência passa a ser um valor, um bem supremo. Diante disso, o homem produziu uma obsessão com a performance. Seu bom desempenho lhe garantirá virilidade e, consequentemente, a certeza de adquirir o passaporte para o mercado da conquista. Ambos, tornaram-se escravos de um mercado da lógica pura do sexo, onde não se medem os sacrifícios para modelar os corpos em função dos modismos da época. Esse cenário conduziu a autora a formular as seguintes questões:

Libertação dos tabus ou tirania da fantasia? Desdramatização ou redução da sexualidade à sensação física? Legitimização do desejo ou desencadeamento da violência? Desabrochamento pessoal ou solidão e miséria sexual? Presa entre as garras das saudosistas do retorno ao passado e das partidárias do cada vez mais, a maioria se interroga sobre o caminho a seguir. (Badinter, 2005, p. 113)

O perigo do feminismo é o de ao lutar pela igualdade dos sexos, esquecer-se de melhorar a relação entre eles. Como as mulheres podem esperar melhoria na qualidade de vida, desconsiderando a relação com os homens? A confusão dos papeis e o apagamento das bordas que delimitavam uma diferença desembocaram em uma série de expectativas carregadas de representações tanto do modelo tradicional como do libertário. As mulheres avançaram e, não deveriam se coadunar com essa vitimização. Caiu, mais sobre os homens, uma exigência de um trabalho de si, uma vez que perderam seus privilégios de dominação. Cabe a eles enfrentarem uma crise identitária.

Concluo, acreditando que desmentir a diferença entre os sexos e os destinos que se desdobram a partir dessa estrutura passou a ser politicamente correto. Por que cada sexo não pode se apropriar da diferença que encarna e gerar, de fato, uma política democrática? Por que temos que ser todos iguais para que haja respeito com as diferenças? 


\section{Nota:}

${ }^{1}$ Este artigo integra-se à minha pesquisa de mestrado em Teoria Psicanalítica, concluída em 2016.

\section{Referências Bibliográficas}

Badinter, E. (2005). Rumo equivocado: o feminismo e alguns destinos. Rio de Janeiro: Civilização Brasileira.

Coelho dos Santos, T. (2001). Quem Precisa de Análise Hoje? O discurso analítico: novos sintomas e novos laços sociais. São Paulo: Bertrand Brasil.

Coelho dos Santos, T. (2006). Sinthoma: corpo e laço social. Transcrição do seminário ministrado por Tania Coelho dos Santos no PPGTP/IP/UFRJ no primeiro semestre de 2005. Rio de Janeiro: SEPHORA/UFRJ, 2006.

Coelho dos Santos, T. (2008a). 1968: A Vacilação Generalizada dos Papéis Sociais. In Soubbotinik, O. M. S. \& Soubbotinik, M. (Orgs.). Enlaces, Psicanálise e Conexões, 1, 313-327. Vitória: Programa de Pós-graduação em letras e história da UFES.

Coelho dos Santos, T. (2008b). Entre Tapas e Beijos: a vacilação dos semblantes da diferença sexual. Latusa - Revista da Escola Brasileira de Psicanálise - Seção Rio de Janeiro. Rio de Janeiro: EBP.

Coelho dos Santos, T. (2009). Não existe pecado do lado de baixo do equador? Revista Cadernos de Psicanálise, 25(28), 121-142. Rio de Janeiro: SPCRJ.

Freud, S. (1976). Um tipo especial de escolha de objeto feita pelos homens (Contribuições à Psicologia do Amor I). In J. Salomão (Trad.). Edição Standard Brasileira das Obras Psicológicas Completas de Sigmund Freud (Vol. 11). Rio de Janeiro: Imago (Trabalho original publicado em 1910).

Freud, S. (1976). Sobre a tendência à depreciação na esfera do amor (Contribuições à Psicologia do Amor II). In J. Salomão (Trad.). Edição Standard Brasileira das Obras Psicológicas Completas de Sigmund Freud (Vol. 11). Rio de Janeiro: Imago (Trabalho original publicado em 1912).

Freud, S. (1976). O Tabu da Virgindade (Contribuições à Psicologia do Amor III). In J. Salomão (Trad.). Edição Standard Brasileira das Obras Psicológicas Completas de Sigmund Freud (Vol. 11). Rio de Janeiro: Imago (Trabalho original publicado em 1917).

Freud, S. (1976). Algumas consequências psíquicas da distinção anatômica entre os sexos. In J. Salomão (Trad.). Edição Standard Brasileira das Obras Psicológicas Completas de Sigmund Freud (Vol. 19). Rio de Janeiro: Imago (Trabalho original publicado em 1925).

Giddens, A. (1993). A Transformação da Intimidade: sexualidade, amor e erotismo nas sociedades modernas. São Paulo: Editora da Universidade Estadual Paulista.

Vieira, M. I. (2016). Par ou ímpar? Uma leitura dos impasses das parcerias amorosas entre homens e mulheres na clínica contemporânea. (Dissertação de mestrado). Universidade Federal do Rio de Janeiro, Rio de Janeiro. 
Lacan, J. (1997). O seminário, livro 7: a ética da psicanálise. Rio de Janeiro: Zahar (Trabalho original publicado em 1959-1960).

Lacan, J. (1998). A significação do falo. Escritos, pp. 692-703. Rio de Janeiro: Zahar (Trabalho original publicado em 1958).

Lacan, J. (1998). A ciência e a verdade. Escritos. Rio de Janeiro: Zahar (Trabalho original publicado em 1965-1966).

Lacan, J. (2003). Complexos familiares na formação do indivíduo. Outros escritos. Rio de Janeiro: Zahar (Trabalho original publicado em 1938).

Lacan, J. (1992). O seminário, livro 17: o avesso da psicanálise. Rio de Janeiro: Zahar (Trabalho original publicado em 1969-1970).

Lacan, J. (1985). O seminário, livro 20: mais, ainda. Rio de Janeiro: Zahar (Trabalho original publicado em 1972-1973).

Lasch, C. (1983). A Cultura do Narcisismo - a vida americana numa era de esperanças em declínio. Rio de Janeiro: Imago.

Miller, J.-A. (2010, jul.). Uma conversa sobre o amor. Opção Lacaniana online nova série, 1(2). Recuperado de: http://opcaolacaniana.com.br/pdf/numero 2/Uma conversa sobre o amor.pdf.

Miller, J.-A. (2003, ago.). Uma partilha sexual. Clique (2). Revista dos Institutos Brasileiros de Psicanálise do Campo Freudiano MG: Instituto de Saúde Mental de Minas Gerais, agosto, 2003. Miller, J.-A. (2004-2005). Pièces detachés - Seminário de Orientação Lacaniana.

Miller, J.-A. (2010, jul.). Minha garota e eu. Opção Lacaniana online nova série, 1(2). Recuperado de: http://www.opcaolacaniana.com.br/pdf/numero 2/minha garota e eu.pdf.

Citacão/Citation: Vieira, M. I. (mai. a out. 2016). O feminismo e seus destinos. Revista aSEPHallus de Orientação Lacaniana, 11(22), 78-85. Disponível em www.isepol.com/asephallus. doi: 10.17852/1809709x.2019v11n22p78-85.

Editor do artigo: Tania Coelho dos Santos.

Recebido/Received: 24/07/2016 / 07/24/2016.

Aceito/Accepted: 05/08/2016 / 08/05/2016.

Copyright: (c) 2013 Associação Núcleo Sephora de Pesquisa sobre o moderno e o contemporâneo. Este é um artigo de livre acesso, que permite uso irrestrito, distribuição e reprodução em qualquer meio, desde que o autor e a fonte sejam citados/This is an open-access article, which permites unrestricted use, distribution, and reproduction in any medium, provided the author and source are credited. 